\title{
Metformin targets Axl and Tyro3 receptor tyrosine kinases to inhibit cell proliferation and overcome chemoresistance in ovarian cancer cells
}

\author{
NAM-YI KIM, HWA-YOUNG LEE and CHUHEE LEE \\ Department of Biochemistry and Molecular Biology, School of Medicine, \\ Yeungnam University, Daegu 705-717, Republic of Korea \\ Received March 18, 2015; Accepted April 30, 2015
}

DOI: 10.3892/ijo.2015.3004

\begin{abstract}
Metformin, the most frequently prescribed anti-diabetic drug, has recently been paid attention as a chemotherapeutic agent. In this study, we demonstrated that metformin decreased the viability of parental as well as cisplatin/taxol-resistant ovarian cancer cells. Its anti-proliferative effect was further demonstrated by dose-dependent reduction of the clonogenic ability of the metformin-treated cells. We next observed the effect of metformin on expression of Axl and Tyro3 receptor tyrosine kinases (RTKs) which belong to the TAM subfamily of RTKs transducing pro-survival and antiapoptotic signals. Metformin treatment of ovarian cancer cells decreased both mRNA and protein levels of Axl and Tyro3 in a dose-dependent manner. Axl promoter activity was also inhibited by metformin, indicating that metformin suppresses Axl and Tyro3 expression at the transcriptional level. Metformin treatment was also found to augment its anti-proliferative effect in SKOV3 and taxol-resistant SKOV3/TR cells transfected with Axl and Tyro3 specific siRNAs, siAxl and siTyro3, respectively, suggesting that metformin might target Axl and Tyro3 RTKs to restrain cell proliferation. In parallel, the level of X-linked inhibitor of apoptosis protein (XIAP), an antiapoptotic molecule, was reduced in the metformin-treated cells. Collectively, our data showed that metformin caused
\end{abstract}

Correspondence to: Dr Chuhee Lee, Department of Biochemistry and Molecular Biology, School of Medicine, Yeungnam University, 317-1 Daemyung-5 Dong, Daegu 705-717, Republic of Korea

E-mail: chlee2@ynu.ac.kr

Abbreviations: AMPK, AMP-activated protein kinase; EGFR, epidermal growth factor receptor; ELISA, enzyme-linked immunosorbent assay; GAS6, growth arrest-specific 6; IL-6, interleukin-6; mTORC, mammalian target of rapamycin complex; RTK, receptor tyrosine kinase; STAT, signal transducers and activators of transcription; XIAP, X-linked inhibitor of apoptosis protein

Key words: Axl, chemoresistance, Erk, metformin, ovarian cancer, STAT3, Tyro3 reduction of Axl and Tyro3 RTKs' expression, inactivation of downstream effectors, and decrease of anti-apoptotic protein level, forming a potent therapeutic strategy to facilitate its anticancer activity as well as to overcome chemoresistance in human ovarian cancer cells.

\section{Introduction}

More than $80 \%$ of ovarian cancer cases are discovered at the advanced stage. When the patients are first diagnosed, they already have metastasis (1). The combination of surgery and chemotherapy is common approach to treat ovarian cancer. Many chemotherapeutic agents including carboplatin, cisplatin and paclitaxel have been used as a single drug or in combination. The study conducted by Einzig et al in 1992, which reported the significant activity of paclitaxel in patients with advanced ovarian cancer (2), established the co-administration of paclitaxel and cisplatin/carboplatin as a standard chemotherapeutic regimen. Since $30 \%$ ovarian cancer patients in advanced stages are non-responders to the first-line chemotherapy and the acquired chemoresistance is also emerged from the initial responders (3), both intrinsic and acquired resistances have been the major causes of low survival rates and poor prognosis. Therefore, it is urgently required to understand the underlying molecular mechanisms involved in such chemoresistance, which can introduce novel attempts to overcome resistance and eventually success to treat ovarian cancer.

In human, there are $>90$ protein tyrosine kinases and 58 of them are receptor tyrosine kinases (RTKs) which are, in turn, divided into 20 families (4). TAM family, a subfamily of RTK, is comprised of three RTK members, which are Tyro3 (alternatively called Sky), Axl (alternatively called Ark and Ufo), and Mer (5). They share common extracellular structures, two immunoglobin-like domains and two fibronectin type III repeats, and conserved kinase domain within cytoplasmic region (6). It has been reported that the typical ligands to interact with TAM RTKs are growth arrest-specific 6 (GAS6) and protein $\mathrm{S}$ which are vitamin K-dependent proteins and transduce many intracellular signals including survival, proliferation, inhibition of apoptosis, adhesion, morphology, invasion and motility (7-9). Indeed, overexpression of TAM 
RTKs as well as GAS6 protein have been observed in the initiation and progression of many cancers (10) such as breast cancer (11), colon cancer (12), gastric cancer (13), leukemias (14), liver cancer (15), melanoma $(16,17)$, ovarian cancer $(18,19)$ and prostate cancer $(20)$. Therefore, targeting TAM RTKs and their ligands might be a potent strategy to control these cancers.

Metformin is the most widely prescribed biguanide to treat type 2 diabetes (21). In addition to the primary effect on glucose metabolism, the antitumorigenic potential of metformin has come to the forefront, since the accumulating evidence suggests its anticancer effects on cell proliferation in various cancers and tumor growth in xenograft model (22-25). The anticancer mechanisms of metformin have been assessed by its ability to activate AMP-activated protein kinase (AMPK), resulting in the concomitant inhibition of mammalian target of rapamycin complex I (mTORC1) activity which plays an important role in protein synthesis and cell proliferation (26-29). Metformin has also been reported to directly inhibit mTORC1 independent of AMPK and to target epidermal growth factor receptor (EGFR) and Akt/mitogenactivated protein kinase (MAPK) which mediate pro-survival and anti-apoptotic signals (30-32).

In this study, we examined the effect of metformin on the expression of Axl and Tyro3 RTKs in both parental and chemoresistant ovarian cancer cells, which affects the viability of these cells. Metformin was found to suppress the expression of both Axl and Tyro3 RTKs at transcriptional level and deactivate downstream signaling molecules such as Erk and signal transducers and activators of transcription 3 (STAT3), which led to significant decrease of cell proliferation through downregulation of anti-apoptotic protein such as XIAP.

\section{Materials and methods}

Reagents and antibodies. Metformin was obtained from Sigma (St. Louis, MO, USA). For western blot analysis, specific antibodies against phospho-Akt, Akt, Axl, phospho-Erk, Erk, phospho-STAT3, STAT3, Tyro3, XIAP and GAPDH and secondary antibodies were obtained from Santa Cruz Biotechnology Inc. (Dallas, TX, USA). Primers for PCR to amplify Axl, Tyro3, and GAPDH were synthesized by Bioneer Inc. (Daejoun, Korea). TRI reagent was from Solgent (Daejoun, Korea). AmpliTaq DNA polymerase was obtained from Roche Inc (Indianapolis, IN, USA).

Cell culture. A2780 and SKOV3 cells were purchased from the American Type Culture Collection and A2780/Cis cells were from Sigma. SKOV3/TR cells, a variant of SKOV3 cells with resistance to taxol, were established as we previously reported. Briefly, SKOV3/TR cells had acquired the taxol resistance via long-term and stepwise exposure of the parental cells to the escalating concentrations of taxol. All of these cells were grown in RPMI-1640 (Gibco BRL, Grand Island, NY, USA) containing 10\% FBS, $2 \mathrm{mM} \mathrm{L-glutamine,} 10 \mathrm{U} / \mathrm{ml}$ penicillin, and $10 \mathrm{~g} / \mathrm{ml}$ streptomycin at $37^{\circ} \mathrm{C}$ in $5 \% \mathrm{CO}_{2}$ in a water-saturated atmosphere.

$R T-P C R$. Cells $\left(3 \times 10^{5}\right)$ were seeded in $60-\mathrm{mm}$ culture dishes and grown overnight at $37^{\circ} \mathrm{C}$ and then treated with the indicated concentrations of metformin for the $48 \mathrm{~h}$. Total RNA was extracted using TRI reagent and subjected to cDNA synthesis and PCR. The specific primers were as follows: Axl, sense 5'-AACCTTCAACTCCTGCCTTCTCG-3' and antisense 5'-CAGCTTCTCCTTCAGCTCTTCAC-3'; Tyro3, sense 5'-GTGTGTGGCTGACTTCGGAC-3' and antisense 5'-CAC GTCCTCCATACACTCCG-3'; GAPDH, sense 5'-GGAGCC AAAAGGGTCATCAT-3' and antisense 5'-GTGATGGCATG GACTGTGGT-3'.

Western blot analysis. Cells were treated with the indicated concentrations of metformin for the $48 \mathrm{~h}$. Whole cell lysates were prepared from those cells using lysis buffer [1\% Triton X-100, $50 \mathrm{mM}$ Tris (pH 8.0), $150 \mathrm{mM} \mathrm{NaCl}, 1 \mathrm{mM}$ PMSF, $1 \mathrm{mM} \mathrm{Na}_{3} \mathrm{VO}_{4}$ and protease inhibitor cocktail]. Protein concentrations were determined using Bio-Rad protein assays. Proteins from whole cell lysates $(20-40 \mu \mathrm{g})$ were separated on $12 \%$ SDS-PAGE, and electrotransferred to nitrocellulose membranes. Membranes were blocked for $30 \mathrm{~min}$ at room temperature in Tris-buffered saline- $0.05 \%$ Tween-20 (TTBS) containing 5\% non-fat dry milk, and then incubated with TTBS containing a primary antibody for $4 \mathrm{~h}$ at room temperature. After 3x10-min washes in TTBS, membranes were incubated with peroxidase-conjugated secondary antibody for $1 \mathrm{~h}$. Following 3 additional 10-min washes with TTBS, protein bands of interest were visualized using an enhanced chemiluminescence detection system $\left(\right.$ Amersham ${ }^{\mathrm{TM}} \mathrm{ECL}^{\mathrm{TM}}$ prime Western Blotting detection reagent; GE Healthcare, Piscataway, NJ, USA).

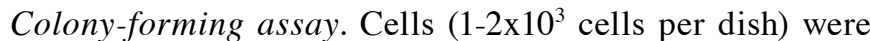
seeded in $35-\mathrm{mm}$ culture dishes and allowed to grow in the absence or presence of the metformin for 7-10 days to form colonies. Colonies of $>50$ cells were visualized by crystal violet (in 60\% methanol, Junsei Chemical, Japan) staining and images were taken by RAS 3000 Image Analysis System (Fuji Film, Japan).

Axl promoter activity test. To measure the Axl promoter activity upon metformin treatment, the plasmid containing Axl promoter-luciferase reporter, pGL3-Axl, was used. As we previously reported, pGL3-Axl plasmid is constructed by PCR amplification of Axl promoter region ranging from -887 to +7 bp of the transcriptional start site and the following subcloning of the PCR product into the pGL3-basic vector. The pGL3-Axl plasmid was co-transfected into cells $\left(3 \times 10^{4}\right.$ cells in a $60-\mathrm{mm}$ dish) with Renilla luciferase vectors, pRL-SV40, as an internal control. Luciferase activity was measured using a Dual-Glo luciferase assay system.

siRNA transfection. RNA interference silencing was performed to suppress Axl or Tyro3 protein levels. SKOV3 or SKVO3/TR cells $\left(1 \times 10^{6}\right)$ were seeded in $100-\mathrm{mm}$ culture dish and grown overnight and then transfected with $50 \mathrm{nM}$ siRNA against Axl (sc-36438, Santa Cruz Biotech), Tyro3 (sc-36438, Santa Cruz Biotech), or control siRNA (sc-37007, Santa Cruz Biotech). For cell proliferation assay, cells were harvested $24 \mathrm{~h}$ after transfection and re-seeded into $35-\mathrm{mm}$ culture dishes and allowed to grow for $48 \mathrm{~h}$ in the absence or presence of the metformin. Cells were then harvested and the number of 
viable cells was counted. Whole cell lysates were prepared and used for western blot analysis to evaluate Axl and Tyro3 protein levels.

ELISA. The level of IL-6 in culture media was measured using ELISA kit from R\&D Systems according to the manufacturer's protocol. Cells were treated with the indicated concentration of metformin for $48 \mathrm{~h}$. Conditioned media were harvested and assayed for IL-6. The data are representative of at least three independent experiments.

Statistical analysis. Data are expressed as the mean \pm SD of triplicate samples or at least three independent experiments. Student's t-test was used to determine statistical significance with a threshold P-value of $<0.05$.

\section{Results}

Metformin inhibits proliferation of both parental and chemoresistant ovarian cancer cells. To determine anti-proliferative effect of metformin on human ovarian cancer cells, A2780 and SKOV 3 cells were incubated with 1,3 and $10 \mathrm{mM}$ of metformin for $48 \mathrm{~h}$ and then cell viability was measured. As shown in Fig. 1A, cell counting results showed that metformin treatment caused dose-dependent reduction of cell proliferation in both cell types. Of note, when the cells were exposed to $10 \mathrm{mM}$ of metformin for $48 \mathrm{~h}$, the number of viable A2780 and SKOV3 cells were diminished to 36 and $33 \%$ of that of untreated cells, respectively. The inhibitory effect of metformin on cell proliferation was further confirmed by colony-forming assay. Exposure of A2780 and SKOV3 cells upon 1, 3 and $10 \mathrm{mM}$ metformin for 7 days were found to form less colonies in a dose-dependent manner (Fig. 1B). Especially, both cell types failed to grow into colonies in the presence of $10 \mathrm{mM}$ metformin, indicating cytotoxic effect of metformin on human ovarian cancer cells

We also found that metformin decreased proliferation of chemoresistant ovarian cancer cells. Cisplatin-resistant A2780/Cis cells and taxol-resistant SKOV3/TR, which are each of subline derived from the parental A2780 and SKOV3 cells, were treated with 1, 3,10 $\mathrm{mM}$ of metformin for $48 \mathrm{~h}$ for cell counting or 7 days for colony-forming assay. As shown in Fig. 1C, the viability SKOV3/TR cells at $10 \mathrm{mM}$ metformin was $37 \%$ of control, while that of A2780/Cis cells was 55\% of control. The result from colony-forming assay also demonstrated that metformin induced a dose-dependent inhibition of cell proliferation (Fig. 1D). It seems to be evident that SKOV3/ TR cells were more profoundly affected by metformin treatment than A2780/Cis cells, since both the cell viability and the number of colonies of SKOV3/TR cells incubated with metformin were less than each of those of A2780/Cis cells exposed to the same concentrations of metformin (Fig. 1C and D). Taken together, these results indicate that metformin decreases proliferative capacity of both parental and chemoresistant ovarian cancer cells, SKOV3, SKOV3/TR, A2780 and A2780/Cis cells.

Metformin suppresses the expression of Axl and Tyro3 RTKS at transcriptional level. Next, we explored if metformin affects the expression of receptor tyrosine kinases (RTKs), since TMA
A

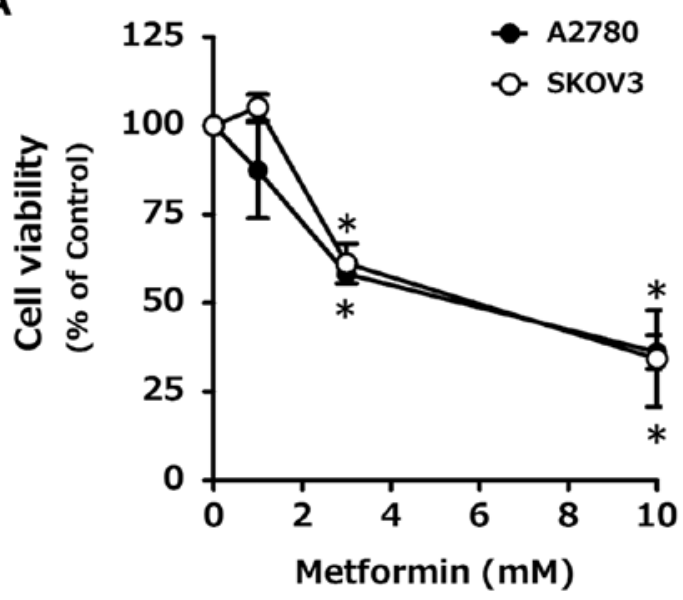

B
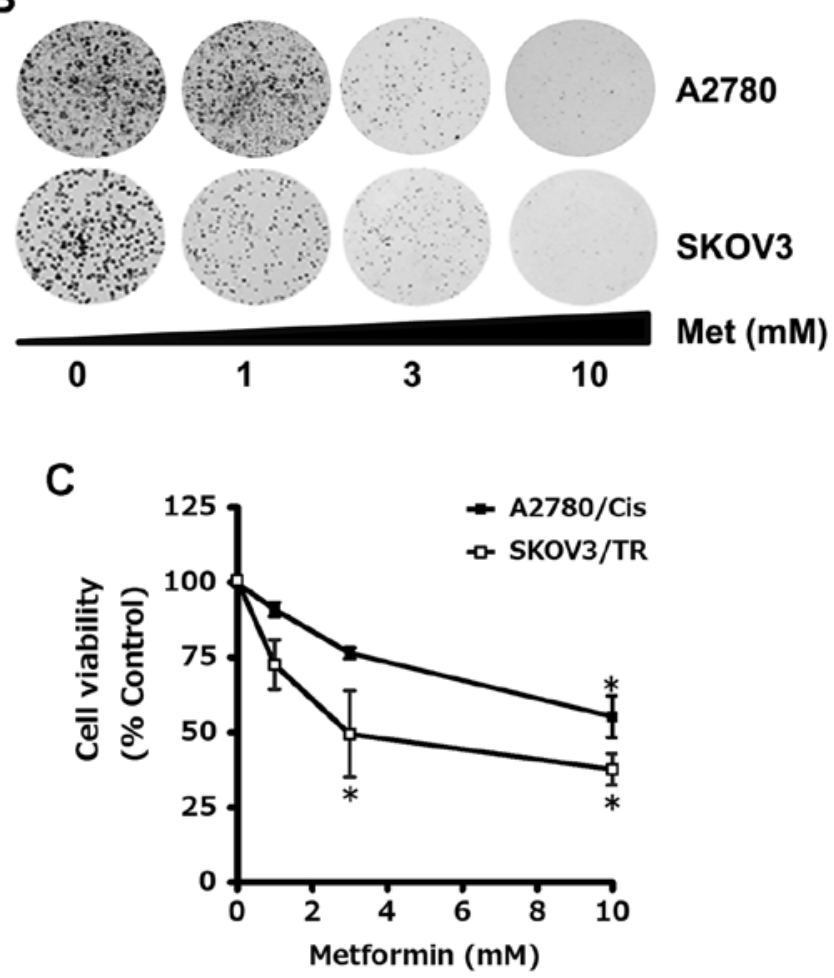

D

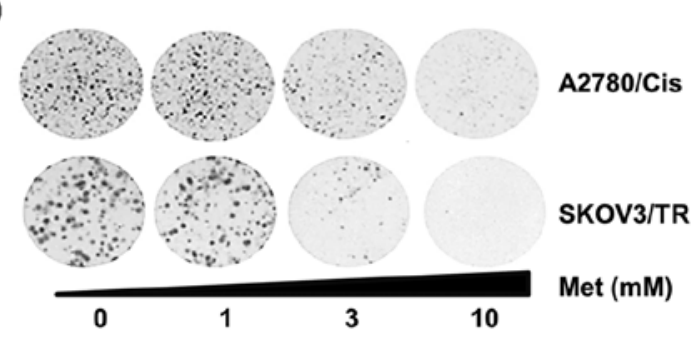

Figure 1. Metformin inhibits proliferation of both parental and chemoresistant resistant ovarian cancer cells. (A and C) Cells $\left(3 \times 10^{3}\right.$ cells/dish) were seeded onto $60-\mathrm{mm}$ dishes, grown overnight and treated with the indicated doses of metformin for $48 \mathrm{~h}$. After treatment, cells were harvested, stained with tryphan blue, and the number of viable cells was counted. Data are presented as mean $\pm \mathrm{SD}$ of at least three independent experiments. The asterisks indicate the significant difference compared to the control value $\left({ }^{*} \mathrm{P}<0.05\right.$ vs untreated group). ( $\mathrm{B}$ and $\left.\mathrm{D}\right) \mathrm{Cells}\left(2 \times 10^{3}\right.$ cells/dish) were seeded onto $35-\mathrm{mm}$ dishes and allowed to grow under the indicated dose of metformin for 7-10 days. Colonies were visualized by crystal violet staining. The data shown is representative of three independent experiments. 
A

\begin{tabular}{|c|c|c|c|c|c|c|c|c|}
\hline \multicolumn{4}{|c|}{ A2780 } & \multicolumn{4}{|c|}{ A2780/Cis } & \multirow[b]{2}{*}{ Met (mM) } \\
\hline 0 & 1 & 3 & 10 & 0 & 1 & 3 & 10 & \\
\hline$=$ & $m$ & - & - & $=$ & in & $=$ & $=$ & $A x I$ \\
\hline$=$ & a & $\sqrt{67}$ & $=$ & 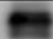 & 0 & 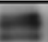 & $=$ & Tyro3 \\
\hline & & & & & & & & GAPDH \\
\hline
\end{tabular}

\begin{tabular}{|c|c|c|c|c|c|c|c|c|}
\hline \multicolumn{4}{|c|}{ SKOV3 } & \multicolumn{4}{|c|}{ SKOV3/TR } & \multirow{3}{*}{$\begin{array}{l}\text { Met (mM) } \\
\text { Axl }\end{array}$} \\
\hline 0 & 1 & 3 & 10 & 0 & 1 & 3 & 10 & \\
\hline$=$ & - & 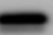 & - & $=$ & - & 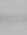 & & \\
\hline- & $\Rightarrow$ & - & $\Rightarrow$ & - & - & & - & Tyro3 \\
\hline & & & & & & & & ATDH \\
\hline
\end{tabular}

B
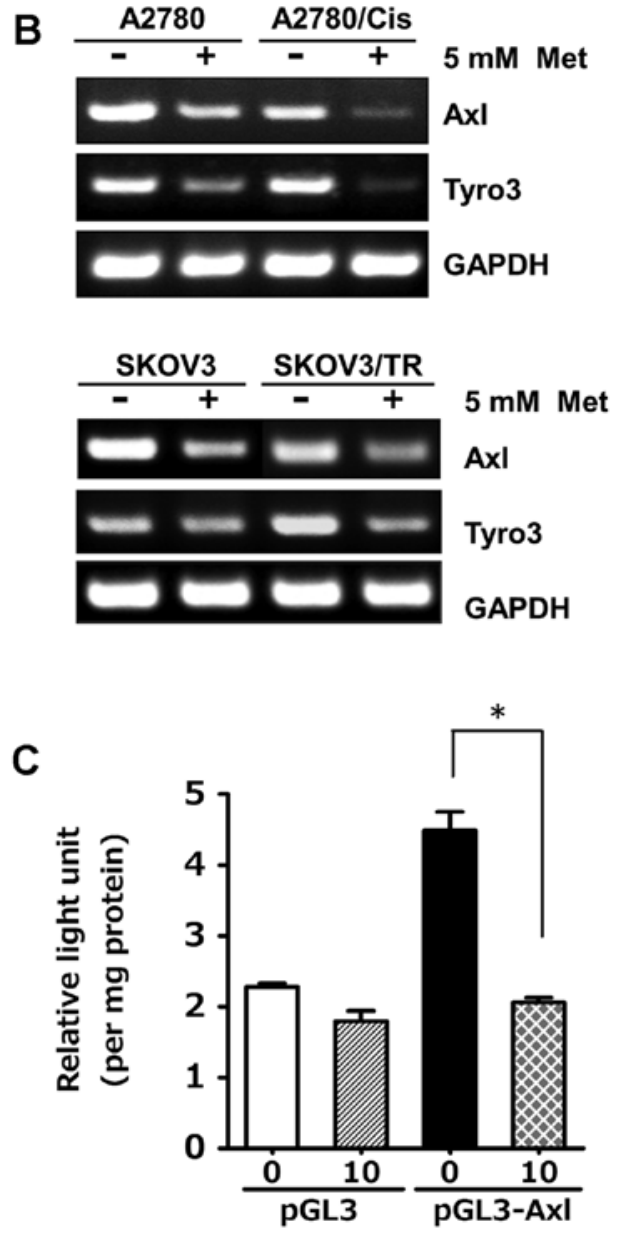

Figure 2. Metformin suppresses the expression of Axl and Tyro3 at transcriptional level. Cells $\left(3 \times 10^{3}\right.$ cells/dish) were seeded onto $60-\mathrm{mm}$ dishes, grown overnight and treated with the indicated doses of metformin for $48 \mathrm{~h}$. (A) The protein levels of Axl and Tyro3 in metformin-treated cells was determined by western blot analysis. GAPDH was used as a loading control. The result shown is a representative of three independent experiments. (B) For RT-PCR, total RNAs from the cells treated with $5 \mathrm{mM}$ metformin for $48 \mathrm{~h}$ were isolated and used for analysis of Axl and Tyro3 mRNA expression. As an internal control, GAPDH mRNA was also amplified by RT-PCR. The data shown are representative of three independent experiments. (C) To examine the effect of metformin on Axl promoter activity, the SKOV3 cells ( $3 \times 10^{4}$ cells) were transfected with pGL3 or pGL3 Axl using Lipofectamine 2000. The cells were then incubated with $10 \mathrm{mM}$ metformin for $24 \mathrm{~h}$ and total cell lysates were used to measure luciferase activity. Data are expressed as the means \pm SD of triplicate samples conducted in three independent experiments. The asterisks indicate the significant difference compared to the control value $(\mathrm{P}<0.05$, vs untreated group).
A

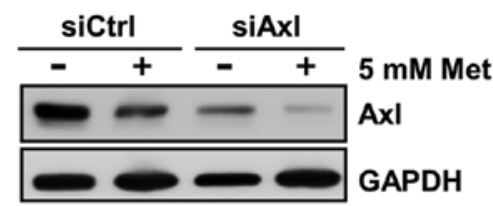

B

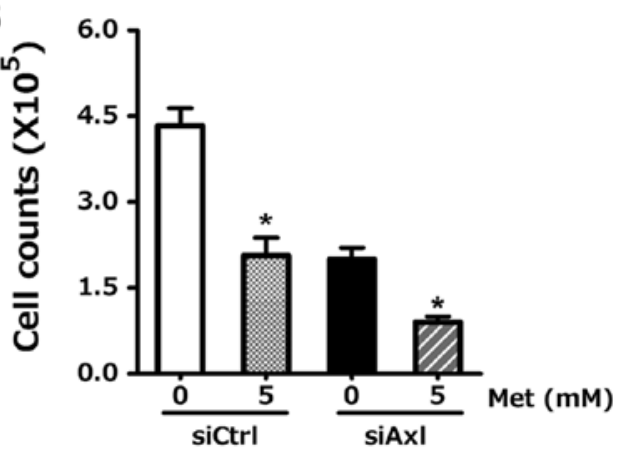

C

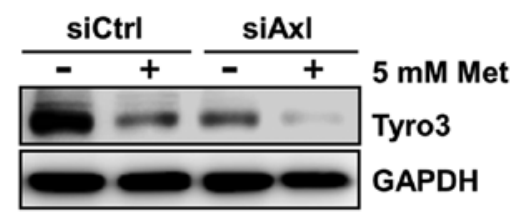

D

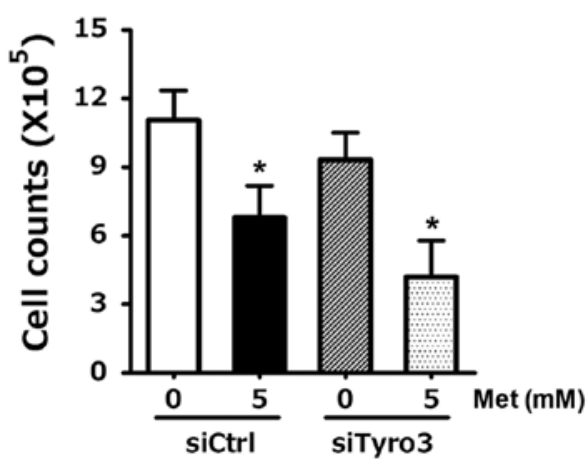

Figure 3. Silencing of Axl or Tyro3 augments the anti-proliferative effects of metformin in ovarian cancer cells. SKOV3 and SKOV3/TR cells ( $3 \times 10^{4}$ cells) were transfected with Axl- or Tyro3-specific siRNA, respectively. The control siRNA was also transfected to the same cells. (A and C) Cells were harvested $24 \mathrm{~h}$ post-transfection, split and treated with the indicated concentrations of metformin for $48 \mathrm{~h}$. The total cell lysates were prepared and the Axl and Tyro3 protein levels were determined by western blot analysis. GAPDH was used as a loading control and results shown are representative of at least three independent experiments. (B and D) After treatment, cells were harvested and the number of viable cells was counted by tryphan blue staining. Data are presented as mean $\pm \mathrm{SD}$ of at least three independent experiments. The asterisks indicate the significant difference compared to the control value $\left({ }^{*} \mathrm{P}<0.05\right.$ vs untreated group)

RTKs, Axl, Tyro3, and Mer, have been reported to mediate cell survival and proliferation signals (33). After exposure of cells with the indicated concentrations of metformin for $48 \mathrm{~h}$, the expression of Axl and Tyro3 was examined at protein and mRNA levels. As shown in Fig. 2A, metformin treatment was found to induce dose-dependent downregulation of Axl and Tyro3 expression in both SKOV3 and taxol-resistant SKOV3/TR cells, while Axl and Tyro3 protein levels in A2780 cells and cisplatin-resistant A2780/Cis cells were significantly reduced upon 1 or $10 \mathrm{mM}$ metformin treatment. 
A

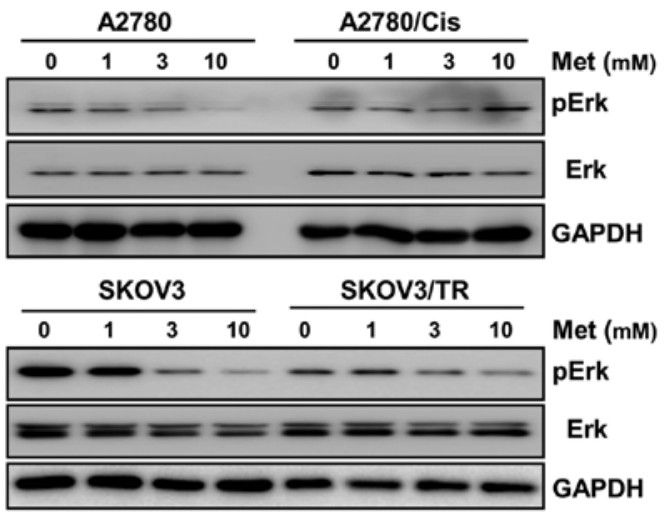

B

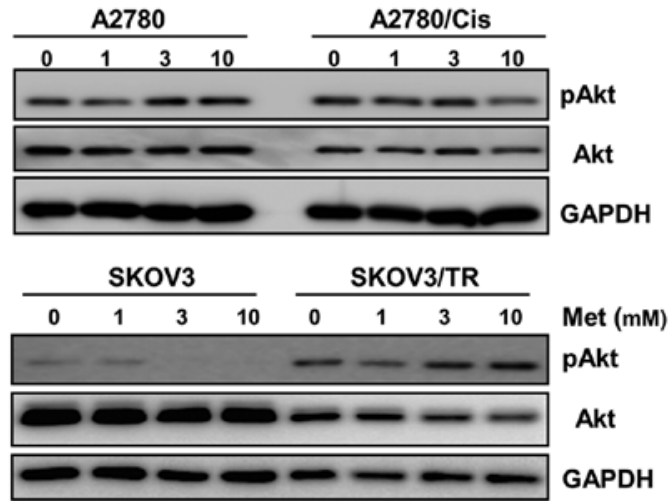

C

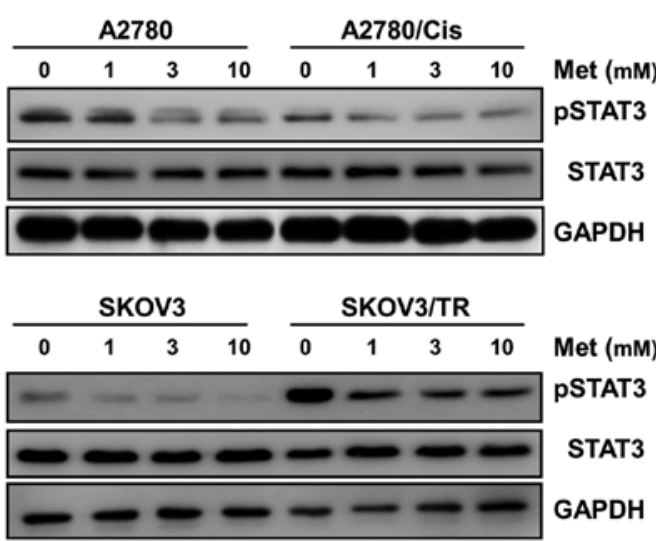

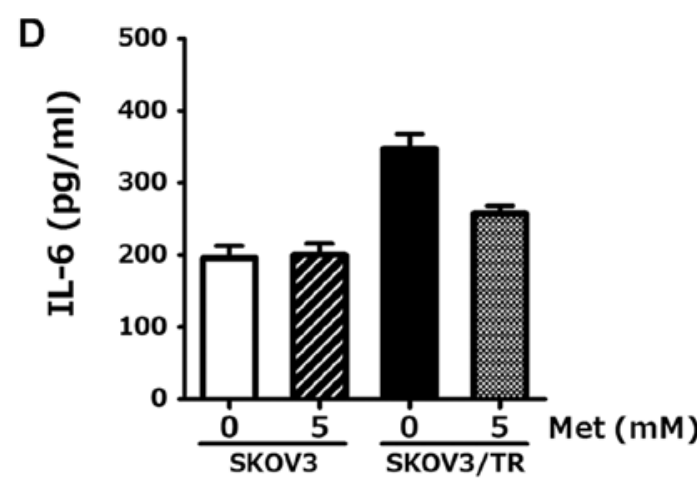

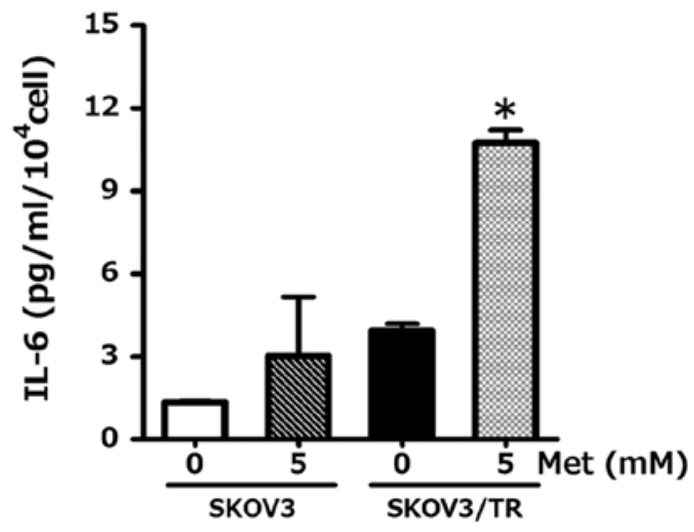

E

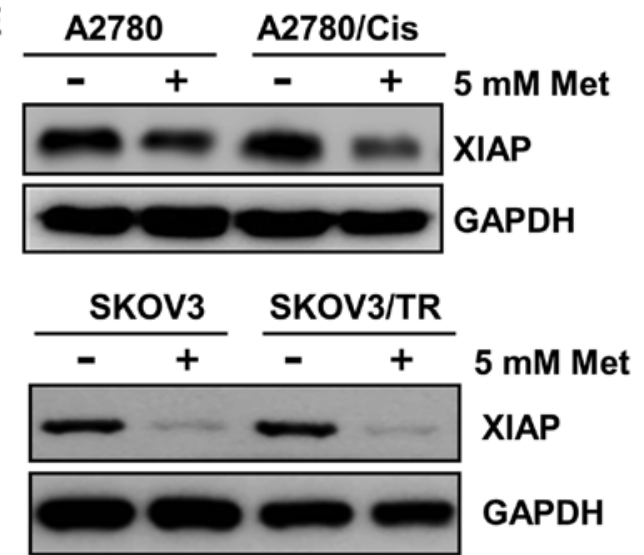

Figure 4. Metformin has inhibitory effect on Erk and STAT3 phosphorylation and XIAP protein level, but not IL-6 production, in ovarian cancer cells. Cells $\left(3 \times 10^{3}\right.$ cells/dish) were seeded onto $60-\mathrm{mm}$ dishes, grown overnight and treated with the indicated doses of metformin for $48 \mathrm{~h}$. (A-C) The total cell lysates were prepared and phospho-Erk, Akt and STAT3 levels were assessed by western blot analysis. Total protein levels of each protein were also analyzed by western blotting. GAPDH was used as a loading control. The result shown is a representative of three independent experiments. (D) In parallel, the conditioned media from metformin treated SKOV3 and SKOV3/TR cells were harvested and used to determine IL-6 protein levels via ELISA. The asterisks indicate the significant difference compared to the control value ("P $<0.05$ vs untreated control). The data are representative of three independent experiments. (E) XIAP protein levels of total cell lysates were also examined by western blot analysis. GAPDH was also detected as a loading control. The data shown are representative of three independent experiments.

The effect of metformin on Axl and Tyro3 expression was further confirmed by RT-PCR. Consistent with western blot results, the mRNA levels of $A x l$ and Tyro3 were decreased by metformin treatment (Fig. 2B). It is notable that Axl mRNA expression was slightly reduced in chemoresistant A2780/ Cis and SKOV3/TR cells, compared to that in their parental cells, while Tyro3 mRNA expression was increased in these two chemoresistant cells, indicating that the acquisition of cisplatin or taxol resistance resulted in the down/upregulation of Axl and Tyro3 expression, respectively.
The inhibitory effect of metformin on the transcription of $A x l$ gene was also demonstrated by promoter activity test. SKOV3 cells were transfected with pGL3-Axl construct, a luciferase expressing plasmid under the control of human Axl promoter and then incubated with $10 \mathrm{mM}$ metformin for $48 \mathrm{~h}$. As illustrated in Fig. 2C, metformin treatment was found to reduce Axl promoter activity to $46 \%$ compared with the untreated cells. The results from RT-PCR and promoter activity test indicate that metformin suppresses Axl expression at the transcriptional level. 
Anti-proliferative effect of metformin is mediated by dysregulation of Axl and Tyro3 RTKs and downstream signaling molecules. We further examined whether the inhibitory effect of metformin on Axl and Tyro3 expression is responsible for its anti-proliferative property. Axl and Tyro3-specific siRNA, siAxl and siTyro3, was transfected into SKOV3 and SKOV3/TR cells, respectively, and then cells were treated with metformin to evaluate the synergistic effect on protein expression as well as cell viability. Western blot results showed that knock-down of Axl and Tyro3 protein level by specific siRNA augmented metformin-induced downregulation of each protein expression (Fig. 3A and C). The viability of the cells transfected with siAxl or siTyro3 was found to be $48 \%$ in SKOV3 cells and $45 \%$ in SKOV3/TR cells, thus being lower than each of the cells transfected with control siRNA, siCtrl (Fig. 3B and D). This indicates that decreased $\mathrm{Axl}$ and Tyro3 protein level by siRNA escalated the inhibitory effect of metformin on cell proliferation. Taken together, these data demonstrate that Axl and Tyro3 RTKs are novel targets of metformin for its anticancer activity in ovarian cancer cells.

We next examined the effects of metformin on several downstream effectors known as regulators of cell survival, proliferation and apoptosis. As shown in Fig. 4A, dosedependent inhibition of Erk phosphorylation by metformin was found in A2780, SKOV3 and SKOV3/TR cells, but not in A2780/Cis cells. On the other hand, metformin was found to have no effect on phosphorylation of Akt which delivers proliferative signals and is elevated in SKOV3/TR cells, except in SKOV3 cells (Fig. 4B).

Western blot analysis further showed that metformin fairly reduced phosphorylation of signal transducers and activators of transcription 3 (STAT3), one of the key regulators driving cell proliferation in both parental and chemoresistant cells (Fig. 4C). Based on metformin-mediated suppression of STAT3 phosphorylation, we also examined IL-6 production upon metformin treatment, since activation of IL-6/STAT3 axis has been known to play an important role in cell viability $(34,35)$. ELISA results showed that total IL-6 production was slightly reduced by metformin, whereas IL-6 production per cell was rather increased (Fig. 4D).

In addition, we observed that the metformin reduced the level of X-linked inhibitor of apoptosis protein (XIAP) which inhibits apoptosis (Fig. 4E). Collectively, these data indicate that metformin induces the downregulation of Axl and Tyro3 expression and the subsequent decrease of Erk and STAT3 phosphorylation as well as XIAP expression by which it exerts its anticancer activity in ovarian cancer cells.

\section{Discussion}

Cisplatin has primarily been approved as an anticancer agent to treat testicular and ovarian cancer in $1978(36,37)$, and is the first-line chemotherapy drug used in many cancers such as bladder, cervical, ovarian cancers, lymphomas and sarcomas, as a single agent or in combination with other anticancer agents, including paclitaxel (38-40). Taxol, a microtubulestabilizing drug, which in turn prevents depolymerization of microtubule, has been frequently used to treat breast, lung, stomach or ovarian cancers (41). Although the combination of platinum-based agent and taxol is still standard chemotherapy regimen in ovarian cancers, most patients eventually develop tolerance against cisplatin and taxol, leading to a low 5-year survival rate $(3,42)$. However, the molecular mechanisms of this chemoresistance are not yet fully understood.

We found that metformin suppressed the viability of ovarian cancer cells (A2780 and SKOV3) and their cisplatin/taxol-resistant cells (A2780/Cis and SKOV3/TR) (Fig. 1). Consistent with our data, the anticancer and chemopreventive effects of metformin have been suggested by many epidemiological and preclinical studies which demonstrated that metformin treatment is associated with the reduction of cancer risk and better prognosis in patients with type II diabetes (43-46). Of note, however, there are also several studies which failed to demonstrate any beneficial effect of metformin (47-49).

We then observed that metformin downregulates the expression of Axl and Tyro3 receptor tyrosine kinases (RTKs) at transcriptional level (Fig. 2). TAM family of RTKs, Tyro3, Axl and Mer, have been reported to play critical roles in cell survival, proliferation, apoptosis, and adhesion (33). Dysregulation of these RTKs and their ligands including GAS6 has been shown in many human cancers. In ovarian adenocarcinoma tissues, the overexpression and activation of Axl, Mer and ligands have been observed and found to be correlated with disease stages and metastasis (19). In acute lymphoblastic leukemia (ALL) and non-small cell lung cancer (NSCLC) cell lines, the Mer expression was found to be elevated to promote cancer cell survival, tumorigenesis and chemoresistance. In addition, Axl or Mer inhibition using RNA interference, monoclonal antibodies and shRNA have been demonstrated to abrogate proliferation, metastasis and tumor progression in xenograft model, while it enhanced chemosensitivity in ALL and NSCLC $(9,50,51)$. Consistent with these reports, we also found that the silencing of Axl and Tyro3 RTKs by specific siRNAs, siAxl and siTyro3, augmented the anti-proliferative effect of metformin in SKOV3 and SKOV3/TR cells, respectively (Fig. 3B and D). Our data suggest that Axl and Tyro3 RTKs might be novel targets of metformin to inhibit cell proliferation as well as to overcome chemoresistance.

A recent study by Feng et al demonstrated that metformininduced inactivation of STAT3 signaling promotes autophagy and apoptosis as a mechanism to inhibit cell growth in esophageal squamous cells (52). In our setting, metformin was found to decrease STAT3 phosphorylation (Fig. 4C). Since STAT3 is a transcription factor to induce IL-6 production and IL-6 phosphorylates STAT3, we examined the effect of metformin on IL-6 expression. Interestingly, metformin was found to have almost no effect of on IL-6 production and IL- 6 production per cell was even shown to be increased upon metformin treatment (Fig. 4D). These results indicate that metformin directly inhibits STAT3 phosphorylation, while cells must somehow have a strategy to compensate the IL-6 production which might provide residual cell viability upon metformin exposure.

In conclusion, our data demonstrate that metformin has inhibitory effects on Axl and Tyro3 expression and subsequent activation of Erk and STAT3, resulting in its anti-proliferative activity in both parental and chemoresistant ovarian cancer cells. Thus, Axl and Tyro3 and/or their downstream signaling pathway seem to be novel therapeutic targets of metformin to 
control proliferation and chemoresistance of ovarian cancer cells.

\section{Acknowledgements}

This study was supported by the by the Basic Science Research Program through the National Research Foundation of Korea (NRF) funded by the Ministry of Education, Science and Technology (grant no. 2006-2005303).

\section{References}

1. Siegel R, Ma J, Zou Z and Jemal A: Cancer statistics, 2014. CA Cancer J Clin 64: 9-29, 2014.

2. Einzig AI, Wiernik PH, Sasloff J, Runowicz CD and Goldberg GL: Phase II study and long-term follow-up of patients treated with Taxol for advanced ovarian adenocarcinoma. J Clin Oncol 10: 1748-1753, 1992.

3. McGuire WP, Hoskins WJ, Brady MF, Kucera PR, Partridge EE, Look KY, Clarke-Pearson DL and Davidson M: Cyclophosphamide and cisplatin compared with paclitaxel and cisplatin in patients with stage III and stage IV ovarian cancer. N Engl J Med 334: 1-6, 1996.

4. Robinson DR, Wu YM and Lin SF: The protein tyrosine kinase family of the human genome. Oncogene 19: 5548-5557, 2000.

5. Ohashi K, Mizuno K, Kuma K, Miyata T and Nakamura T: Cloning of the cDNA for a novel receptor tyrosine kinase, Sky, predominantly expressed in brain. Oncogene 9: 699-705, 1994.

6. Sasaki T, Knyazev PG, Clout NJ, Cheburkin Y, Göhring W, Ullrich A, Timpl R and Hohenester E: Structural basis for Gas6-Axl signalling. EMBO J 25: 80-87, 2006.

7. Stitt TN, Conn G, Gore M, Lai C, Bruno J, Radziejewski C, Mattsson K, Fisher J, Gies DR, Jones PF, et al: The anticoagulation factor protein $\mathrm{S}$ and its relative, Gas6, are ligands for the Tyro 3/Axl family of receptor tyrosine kinases. Cell 80: 661-670, 1995.

8. Hafizi S andDahlbäck B: Gas6 and protein S: Vitamin K-dependent ligands for the Axl receptor tyrosine kinase subfamily. FEBS J 273: 5231-5244, 2006

9. Wimmel A, Glitz D, Kraus A, Roeder J and Schuermann M: Axl receptor tyrosine kinase expression in human lung cancer cell lines correlates with cellular adhesion. Eur J Cancer 37: 2264-2274, 2001.

10. Zwick E, Bange J and Ullrich A: Receptor tyrosine kinase signalling as a target for cancer intervention strategies. Endocr Relat Cancer 8: 161-173, 2001.

11. Meric F, Lee WP, Sahin A, Zhang H, Kung HJ and Hung MC: Expression profile of tyrosine kinases in breast cancer. Clin Cancer Res 8: 361-367, 2002.

12. Craven RJ, Xu LH, Weiner TM, Fridell YW, Dent GA, Srivastava S, Varnum B, Liu ET and Cance WG: Receptor tyrosine kinases expressed in metastatic colon cancer. Int J Cancer 60: 791-797, 1995.

13. Wu CW, Li AF, Chi CW, Lai CH, Huang CL, Lo SS, Lui WY and Lin WC: Clinical significance of AXL kinase family in gastric cancer. Anticancer Res 22B: 1071-1078, 2002.

14. Challier C, Uphoff CC, Janssen JW and Drexler HG: Differential expression of the ufo/axl oncogene in human leukemia-lymphoma cell lines. Leukemia 10: 781-787, 1996.

15. Tsou AP, Wu KM, Tsen TY, Chi CW, Chiu JH, Lui WY, Hu CP, Chang C, Chou CK and Tsai SF: Parallel hybridization analysis of multiple protein kinase genes: Identification of gene expression patterns characteristic of human hepatocellular carcinoma. Genomics 50: 331-340, 1998

16. Györffy B and Lage H: A Web-based data warehouse on gene expression in human malignant melanoma. J Invest Dermatol 127: 394-399, 2007.

17. van Ginkel PR, Gee RL, Shearer RL, Subramanian L, WalkerTM, Albert DM, Meisner LF, Varnum BC and Polans AS: Expression of the receptor tyrosine kinase Axl promotes ocular melanoma cell survival. Cancer Res 64: 128-134, 2004.

18. Macleod K, Mullen P, Sewell J, Rabiasz G, Lawrie S, Miller E, Smyth JF and Langdon SP: Altered ErbB receptor signaling and gene expression in cisplatin-resistant ovarian cancer. Cancer Res 65: 6789-6800, 2005.
19. Rankin EB, Fuh KC, Taylor TE, Krieg AJ, Musser M, Yuan J, Wei K, Kuo CJ, Longacre TA and Giaccia AJ: AXL is an essential factor and therapeutic target for metastatic ovarian cancer. Cancer Res 70: 7570-7579, 2010.

20. Sainaghi PP, Castello L, Bergamasco L, Galletti M, Bellosta P and Avanzi GC: Gas6 induces proliferation in prostate carcinoma cell lines expressing the Axl receptor. J Cell Physiol 204: 36-44, 2005.

21. Donato NJ: Imatinib is receptive to a collaboration. Blood 118: 4009-4010, 2011.

22. Gotlieb WH, Saumet J, Beauchamp MC, Gu J, Lau S, Pollak MN and Bruchim I: In vitro metformin anti-neoplastic activity in epithelial ovarian cancer. Gynecol Oncol 110: 246-250, 2008

23. Wang LW, Li ZS, Zou DW, Jin ZD, Gao J and Xu GM: Metformin induces apoptosis of pancreatic cancer cells. World J Gastroenterol 14: 7192-7198, 2008.

24. Goodwin PJ, Pritchard KI, Ennis M, Clemons M, Graham M and Fantus IG: Insulin-lowering effects of metformin in women with early breast cancer. Clin Breast Cancer 8: 501-505, 2008.

25. Ben Sahra I, Laurent K, Loubat A, Giorgetti-Peraldi S, Colosetti P, Auberger P, Tanti JF, Le Marchand-Brustel Y and Bost F: The antidiabetic drug metformin exerts an antitumoral effect in vitro and in vivo through a decrease of cyclin D1 level. Oncogene 27: 3576-3586, 2008.

26. Hadad SM, Appleyard V and Thompson AM: Therapeutic metformin/AMPK activation promotes the angiogenic phenotype in the ERalpha negative MDA-MB-435 breast cancer model. Breast Cancer Res Treat 114: 391, 2009.

27. Liu H, Scholz C, Zang C, Schefe JH, Habbel P, Regierer AC, Schulz CO, Possinger K and Eucker J: Metformin and the mTOR inhibitor everolimus (RAD001) sensitize breast cancer cells to the cytotoxic effect of chemotherapeutic drugs in vitro. Anticancer Res 32: 1627-1637, 2012.

28. Nair V, Sreevalsan S, Basha R, Abdelrahim M, Abudayyeh A, Rodrigues Hoffman A and Safe S: Mechanism of metformindependent inhibition of mammalian target of rapamycin (mTOR) and Ras activity in pancreatic cancer: Role of specificity protein (Sp) transcription factors. J Biol Chem 289: 27692-27701, 2014.

29. Honjo S, Ajani JA, Scott AW, Chen Q, Skinner HD, Stroehlein J, Johnson RL and Song S: Metformin sensitizes chemotherapy by targeting cancer stem cells and the mTOR pathway in esophageal cancer. Int J Oncol 45: 567-574, 2014.

30. Ota S, Horigome K, Ishii T, Nakai M, Hayashi K, Kawamura T, Kishino A, Taiji M and Kimura T: Metformin suppresses glucose-6-phosphatase expression by a complex I inhibition and AMPK activation-independent mechanism. Biochem Biophys Res Commun 388: 311-316, 2009.

31. Ben Sahra I, Regazzetti C, Robert G, Laurent K, Le MarchandBrustel Y, Auberger P, Tanti JF, Giorgetti-Peraldi S and Bost F: Metformin, independent of AMPK, induces mTOR inhibition and cell-cycle arrest through REDD1. Cancer Res 71: 4366-4372, 2011.

32. Ming M, Sinnett-Smith J, Wang J, Soares HP, Young SH, Eibl G and Rozengurt E: Dose-dependent AMPK-dependent and independent mechanisms of berberine and metformin inhibition of mTORC1, ERK, DNA synthesis and proliferation in pancreatic cancer cells. PLoS One 9: e114573, 2014.

33. Linger RM, Keating AK, Earp HS and Graham DK: TAM receptor tyrosine kinases: Biologic functions, signaling, and potential therapeutic targeting in human cancer. Adv Cancer Res 100: 35-83, 2008.

34. Chang KT, Tsai CM, Chiou YC, Chiu CH, Jeng KS and Huang CY: IL-6 induces neuroendocrine dedifferentiation and cell proliferation in non-small cell lung cancer cells. Am J Physiol Lung Cell Mol Physiol 289: L446-L453, 2005.

35. Block KM, Hanke NT, Maine EA and Baker AF: IL-6 stimulates STAT3 and Pim-1 kinase in pancreatic cancer cell lines. Pancreas 41: 773-781, 2012.

36. Rodriguez LH and Johnson DE: Clinical trial of cisplatinum (NSC 119875) in metastatic renal cell carcinoma. Urology 11: 344-346, 1978

37. Briscoe KE, Pasmantier MW, Ohnuma T and Kennedy BJ: cisDichlorodiammineplatinum(II) and adriamycin treatment of advanced ovarian cancer. Cancer Treat Rep 62: 2027-2030, 1978.

38. Go RS and Adjei AA: Review of the comparative pharmacology and clinical activity of cisplatin and carboplatin. J Clin Oncol 17: 409-422, 1999.

39. Boeckman HJ, Trego KS and Turchi JJ: Cisplatin sensitizes cancer cells to ionizing radiation via inhibition of nonhomologous end joining. Mol Cancer Res 3: 277-285, 2005. 
40. Kelland L: The resurgence of platinum-based cancer chemotherapy. Nat Rev Cancer 7: 573-584, 2007.

41. Kohler DR and Goldspiel BR: Paclitaxel (Taxol). Pharmacotherapy 14: 3-34, 1994.

42. Stordal B, Pavlakis N and Davey R: A systematic review of platinum and taxane resistance from bench to clinic: An inverse relationship. Cancer Treat Rev 33: 688-703, 2007.

43. Jiralerspong S, Palla SL, Giordano SH, Meric-Bernstam F, Liedtke C, Barnett CM, Hsu L, Hung MC, Hortobagyi GN and Gonzalez-Angulo AM: Metformin and pathologic complete responses to neoadjuvant chemotherapy in diabetic patients with breast cancer. J Clin Oncol 27: 3297-3302, 2009.

44. Lai SW, Chen PC, Liao KF, Muo CH, Lin CC and Sung FC: Risk of hepatocellular carcinoma in diabetic patients and risk reduction associated with anti-diabetic therapy: A populationbased cohort study. Am J Gastroenterol 107: 46-52, 2012.

45. Garrett CR, Hassabo HM, Bhadkamkar NA, Wen S, Baladandayuthapani V, Kee BK, Eng C and Hassan MM: Survival advantage observed with the use of metformin in patients with type II diabetes and colorectal cancer. Br J Cancer 106: 1374-1378, 2012.

46. Sadeghi N, Abbruzzese JL, Yeung SC, Hassan M and Li D Metformin use is associated with better survival of diabetic patients with pancreatic cancer. Clin Cancer Res 18: 2905-2912, 2012.
47. Bodmer M, Becker C, Meier C, Jick SS and Meier CR: Use of metformin is not associated with a decreased risk of colorectal cancer: A case-control analysis. Cancer Epidemiol Biomarkers Prev 21: 280-286, 2012.

48. Bodmer M, Becker C, Jick SS and Meier CR: Metformin does not alter the risk of lung cancer: A case-control analysis. Lung Cancer 78: 133-137, 2012.

49. Cossor FI, Adams-Campbell LL, Chlebowski RT, Gunter MJ, Johnson K, Martell RE, McTiernan A, Simon MS, Rohan T, Wallace RB, et al: Diabetes, metformin use, and colorectal cancer survival in postmenopausal women. Cancer Epidemiol 37: 742-749, 2013.

50. Linger RM, Keating AK, Earp HS and Graham DK: Taking aim at Mer and Axl receptor tyrosine kinases as novel therapeutic targets in solid tumors. Expert Opin Ther Targets 14: 1073-1090, 2010.

51. Lee-Sherick AB, Eisenman KM, Sather S, McGranahan A, Armistead PM, McGary CS, Hunsucker SA, Schlegel J, Martinson H, Cannon C, et al: Aberrant Mer receptor tyrosine kinase expression contributes to leukemogenesis in acute myeloid leukemia. Oncogene 32: 5359-5368, 2013.

52. Feng Y, Ke C, Tang Q, Dong H, Zheng X, Lin W, Ke J, Huang J, Yeung SC and Zhang $\mathrm{H}$ : Metformin promotes autophagy and apoptosis in esophageal squamous cell carcinoma by downregulating Stat3 signaling. Cell Death Dis 5: e1088, 2014. 